\title{
COPPER INHIBITION OF PHOTOSYSTEM II ACTIVITY IN THE CYANOPHAGE AS-1-RESISTANT MUTANT
}

\author{
S. L. GUPTA \\ Microbiology Unit, Botanical Survey of India, \\ Howrah-711-103, India
}

(Received May 12, 1987)

\begin{abstract}
Copper inhibited the photoreduction of DCPIP (PS II activity) in a spheroplast preparation of cyanophage AS-1-resistant mutant (An/AS-1). The inhibitory action of $\mathrm{Cu}^{2+}$ was reversed by supplementation with manganese but not with DPC. The results suggest that the site of inhibition was either between the $\mathrm{Mn}^{2+}$ and DPC donation site(s) or close to DPC donation site. Protection of the Hill activity by EDTA further suggestes that $\mathrm{Cu}^{2+}$ interacted with the reaction center.
\end{abstract}

In general, all heavy metals at higher concentrations are toxic to algae. Some heavy metals including copper $\left(\mathrm{Cu}^{2+}\right)$ are required in trace amounts by cyanobacterial species for various metabolic processes. The discovery of a number of cyanophages $(1-3)$ provides an ideal system to understand the physiological and genetic nature of cyanobacteria and cyanophage resistant mutants (4). Recently it has been demonstrated in the unicellular cyanobacterium Anacystis nidulans and its cyanophage AS-1 resistant mutant that $\mathrm{Cu}^{2+}$ specifically affects the growth, photosynthetic pigment synthesis (5), uptake and reduction of nitrate (6), acid and alkaline phosphatase activities (7). Pleiotropic behaviour of the cyanophage AS-1 resistant mutant has also been reported (8). Although there are many reports suggesting that $\mathrm{Cu}^{2+}$ has a specific inhibitory effect on photosynthetic reactions such as the Hill reaction, when it is added in toxic amounts $(9,10)$, the possible action site of $\mathrm{Cu}^{2+}$ remains uncertain. The present communication deals with the action of $\mathrm{Cu}^{2+}$ on the Hill activity carried out with the spheroplasts of the cyanophage AS-1-resistant mutant.

MATERIALS AND METHODS

Organism and culture conditions. The cyanophage AS-1-resistant mutant,

Address reprint requests to: Dr. S. L. Gupta, Microbiology Unit, Botanical Survey of India, Howrah-711 103, India. 
designates as An/AS-1, was isolated by double-agar layer techniques following the infection of cyanophage AS-1 with the unicellular cyanobacterium Anacystis nidulans ATCC 27144, which was obtained through the courtesy of Dr. R. S. Safferman, Environmental Protection Agency, University of Cincinati, Ohio, USA. The An/AS-1 mutant was isolated with a frequency of $4 \times 10^{-6}$. No reversion mutation frequency has been observed during the subsequent subculturing. The mutant was grown and maintained in Allen's medium (11) supplemented with A-5 trace elements. The cultures were maintained at $24 \pm 1{ }^{\circ} \mathrm{C}$ and illuminated for 14 days with cool daylight fluorescent tubes (energy flux density $3.87 \mathrm{~W} / \mathrm{m}^{2}$ on the surface of culture vessel).

Preparation of spheroplasts. $\log$ phase cultures $\left(10^{7}\right.$ cells $\left.\cdot \mathrm{ml}^{-1}\right)$ were harvested by centrifugation, suspended in phosphate buffer $(40 \mathrm{mM}, \mathrm{pH} 7)$ containing 0.05 $0.1 \%$ lysozyme and sucrose $(0.4 \mathrm{M})$ and incubated at $37^{\circ} \mathrm{C}$. After $3 \mathrm{~h}$ of incubation, the suspension was centrifuged at a low speed $(1,000 \times g, 5-10 \mathrm{~min})$ to remove cell debris and unbroken cells. The pellet was discarded and the supernatant was again centrifuged $(3,500 \times g, 15 \mathrm{~min})$. The pellet was resuspended in the preparation medium containing phosphate buffer $(\mathrm{pH} 7.2,40 \mathrm{~mm})$, sucrose $(0.2 \mathrm{M})$ and $\mathrm{NaCl}$ $(0.2 \mathrm{M})$.

Measurement of PS II activity. Light from a projection lamp $(500 \mathrm{~W})$ was filtered through a $2.5 \mathrm{~cm}$ thick water column and focussed on the $2.5 \mathrm{ml}$ cuvette. The light intensity of the surface of vessel was $20 \mathrm{~W} / \mathrm{m}^{2}$ and the temperature was kept between $25-27^{\circ} \mathrm{C}$. In the reaction mixture containing spheroplasts (eqvit. to $2.1-$ $2.26 \mathrm{mg} \mathrm{Chl} \cdot \mathrm{ml}^{-1}$ ), 2,6 dichlorophenol indophenol (DCPIP) was added in such a way that its final concentration became $40 \mathrm{~mm}$. Before illumination the reaction mixtures containing spheroplasts were preincubated for $1 \mathrm{~h}$. The dye reduction was followed spectrocolorimetrically at $680 \mathrm{~nm}$ at regular intervals of 30 or $60 \mathrm{~s}$. Reaction mixture incubated in dark served as the control. Manganese $\left(\mathrm{Mn}^{2+}\right), 1,5$ diphenyl carbazide (DPC) and ethylene diamine tetra acetic acid (EDTA) were added in the reaction mixture as needed.

Chemicals. 2,6 Dichlorophenol indophenol (DCPIP), 1,5-diphenyl carbazide (DPC) and ethylene diamine tetraacetic acid (EDTA) were obtained from Sigma Chemicals. $\mathrm{Cu}^{2+}$ (used as $\mathrm{CuSO}_{4} \cdot 5 \mathrm{H}_{2} \mathrm{O}$ ) and $\mathrm{Mn}^{2+}$ (used as $\mathrm{MnCl}_{2} \cdot 2 \mathrm{H}_{2} \mathrm{O}$ ) were obtained from British Drug Houses, India.

\section{RESULTS AND DISCUSSION}

The measurement of electron transport from $\mathrm{H}_{2} \mathrm{O}$ to DCPIP shwed that $\mathrm{Cu}^{2+}$ inhibited PS II activity in a concentration-dependent manner, i.e., linearly against logarithmic increase in $\mathrm{Cu}^{2+}$ concentrations. The concentration required for $50 \%$ inhibition was about $5 \times 10^{-6} \mathrm{M}$ and complete inhibition was achieved when $\mathrm{Cu}^{2+}$ reached $5 \times 10^{-5} \mathrm{M}$ (Fig. 1).

The addition of DPC $(2.5 \mu \mathrm{M})$ or $\mathrm{Mn}^{2+}(2.5 \mu \mathrm{M})$ increased the dye reduction in comparison to the control (Figs. 2 and 3). The dye reduction in the presence of DPC was $8 \mu \mathrm{mol} \cdot \mathrm{mg} \mathrm{Chl}^{-1}$ after $4 \mathrm{~min}$ of treatment, which comes down to $7.5 \mu \mathrm{mol} \cdot \mathrm{mg}$ 


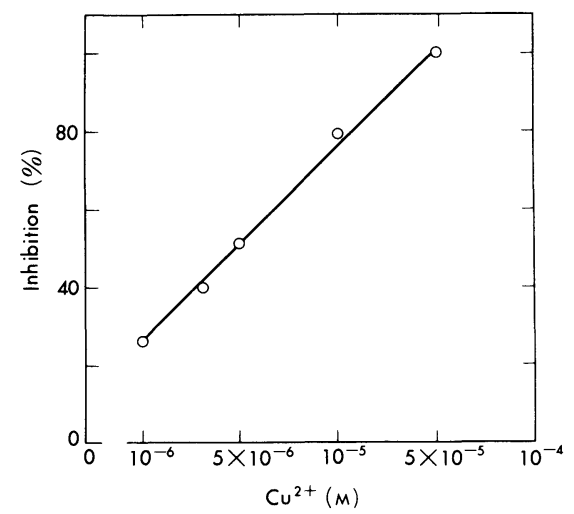

Fig. 1.

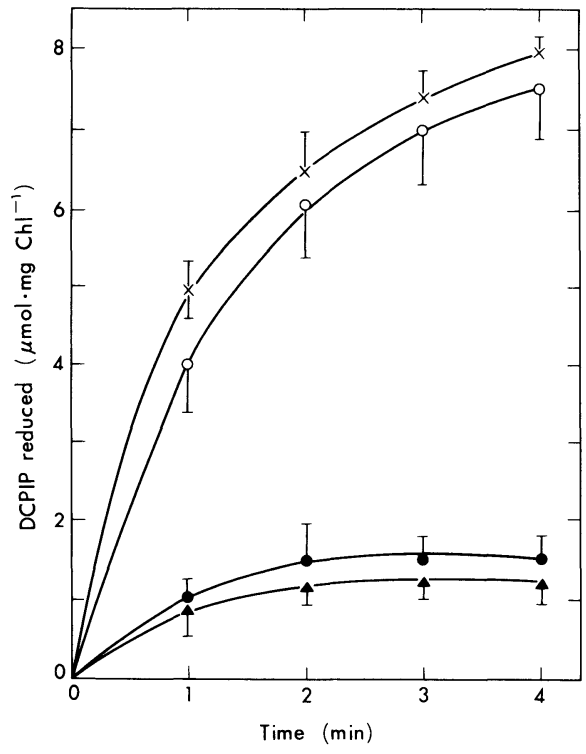

Fig. 2.

Fig. 1. Inhibition of DCPIP reduction by different concentrations of $\mathrm{Cu}^{2+}$ in the spheroplasts of An/AS-1. The data are based on rate of dye-reduction ( $\mu$ mol DCPIP reduced per $\mathrm{mg}$ of $\mathrm{Chl} \cdot \mathrm{min}^{-1}$ ).

Fig. 2. Time course of DCPIP reduction in spheroplasts of An/AS-1 in presence

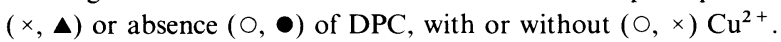

$\mathrm{Chl}^{-1}$ when $\mathrm{Cu}^{2+}$ was added. Thus, in the presence of $\mathrm{Cu}^{2+}$, DPC had no stimulatory effect. It is quite possible that the mode of PS II inhibition by $\mathrm{Cu}^{2+}$ in cyanobacterial cells could be very similar to that in spinach chloroplasts $(10)$. The conclusion stems from the observation that $\mathrm{Mn}^{2+}$ partially reversed the inhibitory action of $\mathrm{Cu}^{2+}$. The recovery of Hill activity by $\mathrm{Mn}^{2+}$ was rapid. Within 2 min, a $54 \%$ stimulation was observed in comparison to $\mathrm{Cu}^{2+}$ inhibition (Fig. 3). $\mathrm{Mn}^{2+}$ is known to donate electrons between the water splitting site and the PS II reaction centre (12), and competes successfully with water as an electron donor to PS II (13). The presence or absence of EDTA $(5-50 \mu \mathrm{M})$ has little effect on DCPIP reduction (Fig. 4). In contrast, when EDTA was added to the reaction mixture containing $\mathrm{Cu}^{2+}$, the dye reduction was higher than in the presence of $\mathrm{Cu}^{2+}$ alone. Considering the level of $\mathrm{Cu}^{2+}$ inhibition $(40 \%)$ the protection afforded by EDTA was approximately $25 \%$ during the course of the experiment. DPC did not protect the system from $\mathrm{Cu}^{2+}$ inhibition. This indicates that $\mathrm{Cu}^{2+}$ inhibited the electron transport before the $\mathrm{Mn}^{2+}$ donation site. The above observations have summarized in a tentative model (Fig. 5) which illustrates the possible target site and mode of action of the different chemicals used and the probeble site of $\mathrm{Cu}^{2+}$ inhibition. 


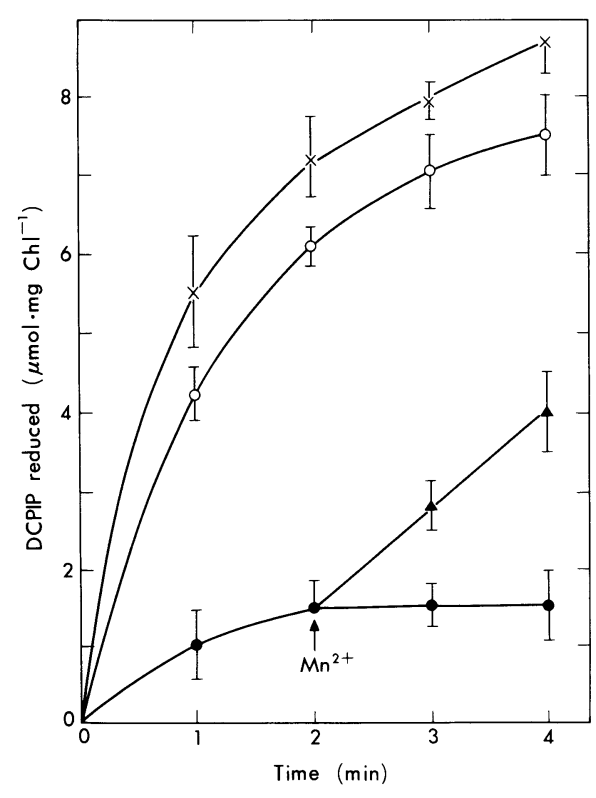

Fig. 3.

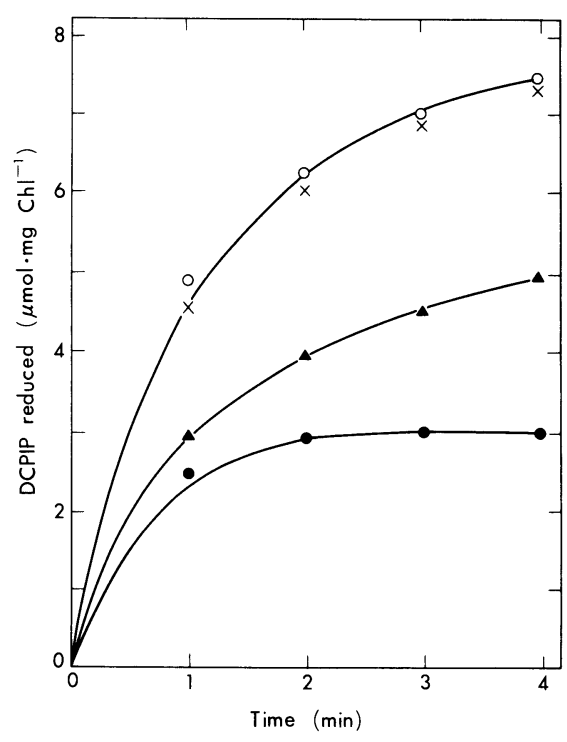

Fig. 4.

Fig. 3. Time course of DCPIP reduction in spheroplasts of An/AS-1 in presence $(\times, \mathbf{\Delta})$ or absence $(O, \bullet)$ of $\mathrm{Mn}^{2+}$ with $(\bullet, \mathbf{\Delta})$ or without $(O, \times) \mathrm{Cu}^{2+} \cdot \mathrm{Mn}^{2+}(\mathbf{\Delta})$ was added at the time indicated by the arrow.

Fig. 4. Time course of DCPIP reduction in spheroplasts of An/AS-1 in the absence $(O, \times)$ or presence $(\bullet, \mathbf{\Delta})$ of $\mathrm{Cu}^{2+}$ with $(\times, \mathbf{\Delta})$ or without $(O, \bullet)$ EDTA.

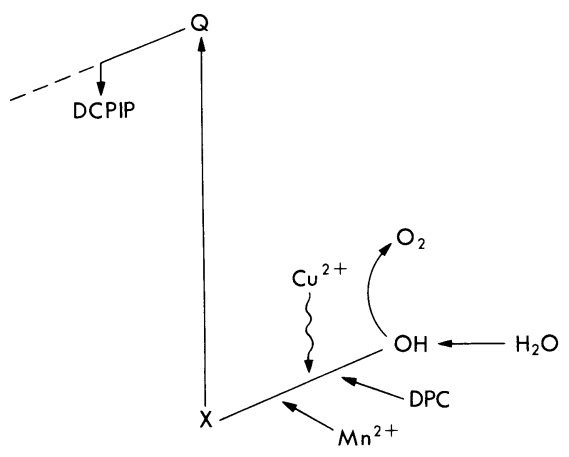

Fig. 5. Model for possible target site of $\mathrm{Cu}^{2+}$ action.

Thanks are due to the Director, Botanical Survey of India for encouragement and to Dr. A. K. Kashyap, Centre of Advanced Study in Botany, Banaras Hindu University for suggesting additional experiments and criticisms. 


\section{REFERENCES}

1) R. S. Safferman and M. E. Morris, J. Bacterol., 88, 77 (1964).

2) E. Padan, M. Shilo, and M. Kisler, Virology, 32, 234 (1967).

3) R. N. Singh and P. K. Singh, Nature, 216, 1020 (1967).

4) B. SAmimi and G. Drews, J. Virol., 25, 164 (1978).

5) S. L. Gupta, Photosynthetica, 20, 447 (1986).

6) A. K. Kashyap and S. L. Gupta, Z. Pflanzenphysiol., 107, 289 (1982).

7) S. L. Gupta, Folia Microbiol., 28, 458 (1983).

8) A. K. Kashyap and S. L. Gupta, Mol. Gen. Genet., 185, 365 (1982).

9) H. M. Habermann, Plant Physiol., 44, 331 (1969).

10) Y. Shiol, H. Tamai, and T. Sasa, Plant Cell Physiol., 19, 203 (1978).

11) M. M. Allen, J. Phycol., 4, 1 (1968).

12) G. Ben-Hayyim and M. Avron, Biochim. Biophys. Acta, 205, 86 (1978).

13) L. J. Rogers, J. W. Owen, and M. E. Delaney: In II Intern. Cong. Photosynthesis, ed. by G. Forti, M. Avron, and A. Malandri, The Hague (1971), p. 689. 